\title{
Arterial Patterns of the Rat Rhinencephalon and Related Structures
}

\author{
Pȟler COYle ${ }^{1}$ \\ Departnent of Anatomy, The Unizersity of Michigan, \\ Ann Arbor, Michigan 48104 \\ Received June 7, 1975
}

\begin{abstract}
Course and distribution information on arteries in the rat rhinencephalon was not found in the literature. Such data are useful for designing experiments and interpreting findings, tracing nerve fibers on or to intracerebral vessels, and in considering routes for diffusion or transport of intracerebral injected agents. Adult rats were perfused with silicone rubber and many brains were cleared in glycerin. The major arteries to the olfactory bulb stem from the anterior cerebral artery. A middle cerebral arterial ramus could provide a collateral source. The septum receives supply exclusively from the anterior cerebral artery. A rostral lesion in the medial septum would most likely involve arteries supplying more caudal structures including hippocampal afferent and efferent fibers. No anastomoses between septal arteries or with middle or posterior cerebral arterial rami were observed. The cingulate cortex receives anterior cerebral arterial branches with the middle cerebral artery being a collateral source. The amygdala and overlying cortex receive branches of the internal carotid and middle cerebral arteries. Transverse arteries in the hippocampal fissure stem from the longitudinal hippocampal artery, a branch of the posterior cerebral artery, to nourish the hippocampus and portions of the fascia dentata. Other branches supply the remainder of the fascia dentata, entorhinal and subicular structures, and certain vessels anastomose with middle cerebral arterial rami. A transverse artery occlusion would probably result in a lesion: No intracerebral arterial anastomoses were observed. Vascular compensation may occur following occlusion of the longitudinal artery via supply from the middle cerebral artery.
\end{abstract}

\section{INTRODUCTION}

Suprisingly, a detailed account of the gross vasculature of the adult rat brain was not found in the literature. Greene (30) and Craigie (59)

1 The author expresses appreciation to Dr. E. W. Lauer for his editorial assistance and for proofreading the manuscript, and to Miss Anita Green for typing it. I wish to thank Mr. W. L. Brudon for assistance in preparation of the figures, and The University of Michigan Medical School for publication support. 
described and illustrated the superficial course of the three major cerebral arteries. Moffat (44-46) investigated the embryology of developing arteries and Craigie identified the choroidal arteries. Brown (10) investigated the circle of Willis and described anatomical variations. Supplies to specific structures or regions were studied. Spoerri (54) investigated the supply to the subfornical organ; Green and Harris (29), Glydon (28), Akmayev (4), Duvernoy (22), and Halasz et al., (31) the pituitary gland; Weindl and Joynt (58) and Weindl (57) the circumventricular organs; Scremin (52) the hypothalamus; and Coyle (12) the septum. Coyle (11) investigated deep veins of the hippocampus.

More attention was given the relative vascularity of different brain structures in the normal rat. Much of the microvessel work was reported by Craigie (14-16) and phylogenetic considerations of the patterns were considered by Craigie (17). Tsang $(55,56)$, Reiniš (50) and others contributed to early microvessel experimental studies in rat. These earlier investigations were reviewed by Freide (24).

Nilges (47) investigated the arterial supply to the hippocampus in dog, cat, monkey. opposum, guinea pig, and rabbit, but did not report on rat. Prolo and Stilwell (49) investigated the rabbit with attention focused on the diencephalon. Abbie $(1,3)$ and Gillilan $(25,26)$ investigated a series of submammals and mammals with emphasis on phylogenetic trends.

Motivations to undertake the present investigation mapping gross arterial distributions in adult rat rhinencephalon ${ }^{2}$ were as follows. First, many different types of experimental procedures on the brain interrupt the vasculature. Experiments should be designed to minimize vascular involvement and should control for damage to "vessels of passage" supplying

2 The term rhinencephalon is used to include the structures grouped under this heading by Crosby et al (18). Regions of the rhinencephalon include the olfactory bulb and associated structures, the amygdaloid nuclei and associated cortex, the septum, cingulate cortex, retrosplenial cortex, and hippocampal formation. The term rhinencephalon is not meant to imply any specific functional organization. The term hippocampal formation is used to include the various fields of the hippocampus [or Cornu Ammonis (CA) segments CA1-4 as designated by Lorente de Nó (43)], the fascia dentata, and subicular and entorhinal fields. Attempts to distinguish various subfields of CA3 external to the hilum of the fascia dentata were not warranted by virtue of the type of specimen observed and distinctions are not made in this report. The longitudinal axis of the hippocampus will refer to the axis extending towards the septum in one direction and towards the temporal region in the other. The transverse hippocampal axis refers to the axis normal to the longitudinal one. The two blades of the fascia dentata were named in reference to their position to the hilum formed by CA1-3. The external blade of the fascia dentata is external to the hilum and on the side of the extraventricular alveus. The internal one borders the hippocampal fissure. Such terminology is utilized to avoid the necessity for translation at different septal-temporal locations and yet maintain correct orientation of reference points. 
more distal structures. Second, following intracerebral administration of drugs, labeling compounds, and the like, some diffusion in the extracellular space along blood vessels and, possibly, active transport occur. Information should be available indicating the spatial organization of all transport systems. Third, Hartman and Udenfriend (33) and Hartman (32) presented evidence for catecholamine axons ascending from the hindbrain tegmental gray to supply vessels directly at forebrain levels. Certainly, spatial maps of vessels are required before vascular innervation fields of myelinated and unmyelinated fibers, as observed by Huber (36), and those on intracerebral vessels demonstrated by Clarke (13), and cholinergic fibers as suggested by the work of Penfield (48) and others, and the catecholamine innervations as reported by Hartman, can be fully clarified.

\section{MATERIALS AND METHODS}

Seventy-five rats, mostly females, of the Wistar strain and weighing from 150-300 g were anesthetized with sodium pentobarbital $(50 \mathrm{mg} / \mathrm{kg}$ body weight, ip). The thoracic cavity was opened on the ventral side, the right atrium was snipped, and in most cases General Electric RTV silicone rubber was perfused via a blunt end hypodermic needle inserted through the left ventricle into the aorta. This vessel was ligated distal to the left common carotid artery. This material thoroughly mixed with India ink or mercuric oxide to provide color was injected under hand pressure in five animals. In some specimens sodium nitrite, a vascular dilating agent, was injected, in others heparin was utilized, or $10 \%$ neutral buffered formalin was injected before the silicone rubber was perfused. These modifications did not appear to enhance the degree of perfusion and result in less satisfactory perfusion when India ink is utilized. Ten brains were either sectioned in one of three standard anatomical planes or dissected and then placed in glycerin for tissue clearing purposes. Undissected brains were macerated in $3 \%$ potassium hydroxide for several days, washed, dehydrated in alcohol, and then placed in glycerin or placed in glycerin directly after fixation or maceration. Observations on the whole and dissected brains were made with the aid of a dissecting microscope. Tissue sections were investigated with a dissecting microscope and a light microscope.

The atlas of Konig and Klippel (39), the monograph of Andy and Stephan (5), and the report of Fox (23) were utilized in studying the septum. Nomenclature for the hippocampal formation (see footnote 2) and associated structures follows definitions established earlier by Lorente de Nó $(42,43)$, Blackstad (8), Krieg $(40,41)$, and Blackstad et al. (9), except where noted. The vascular patterns described below were observed in numerous sections, dissections, and prepared spccimens. Variations occur in number and distribution of the smaller as well as certain of the larger vessels. 
TABLE 1

Abbreviations in Figures

Amygdaloid as.: amygdaloid arterics

Ant. cereb. a.: anterior cerebral artery

Ant. chor, a. : anterior choroidal artery

Az. part, ant. cereb. a.: azygos part anterior cerebral artery

Bas. a. : basilar artery

$\mathrm{Br}$. of long. hipp. a. : branch of longitudinal hippocampal artery

Br. of mid. cereb. a.: branch of middle cerebral artery

Brs. of post. med. chor. a.: branches of posterior medial choroidal artery

$\mathrm{Br}$. to lat. olfact. tr. : branch to lateral olfactory tract

$\mathrm{Br}$. to med. tub. olfact.: branch to medial tuberculum olfactorium

Br. to optic $n$. : branch to optic nerve

$\mathrm{Br}$. to paravent. $\mathrm{n}$. : branch to paraventricular nucleus

Brs. to periam. c.: branches to periamygdaloid cortex

Brs. to pirif. c. : branches to piriform cortex

Com. chor. a. : common choroidal artery

Dors.-lat. olfact. b. a. : dorsal-lateral olfactory bulb artery

Dors.-med. olfact. b. a. : dorsal-medial olfactory bulb artery

Ext. as. to fascia dentata: external arteries to fascia dentata

Int. carotid a. : internal carotid artery

Long. hipp. a.: longitudinal hippocampal artery

Long septal a. : long septal artery

Mid. cereb. a. : middle cerebral artery

Nasal-olfact. a.: nasal olfactory artery

Olfactofrontal a. : olfactofrontal artery

Post. cereb. a. : posterior cerebral artery

Fost. comm. a. : posterior communicating artery

Post. lat. chor. a. : posterior lateral choroidal artery

Septal as.: septal arteries

Stria med. thal. : stria medullaris thalami

Subfornical a.: subfornical artery

Sup. cerebel. a. : superior cerebellar artery

Thalamoperf. a. : thalamoperforating artery

Trans. collic. a.: transverse collicular artery

Trans. hipp. a.: transverse hippocampal artery

Vent.-lat. olfact. b. a. : ventral-lateral olfactory bulb artery

Vent.-med. olfact. b. a.: ventral-medial olfactory bulb artery

Vent. olfact. a. : ventral olfactory artery

Vert. a.: vertebral artery

Important variations are included in the text material, but the study suffers from a lack of quantification of variations.

\section{OBSERVATIONS AND COMMENTS}

Arterial supply of the olfactory bulb, tuberculum olfactorium, and associated structures. The major arterial supply of the olfactory bulb is through 


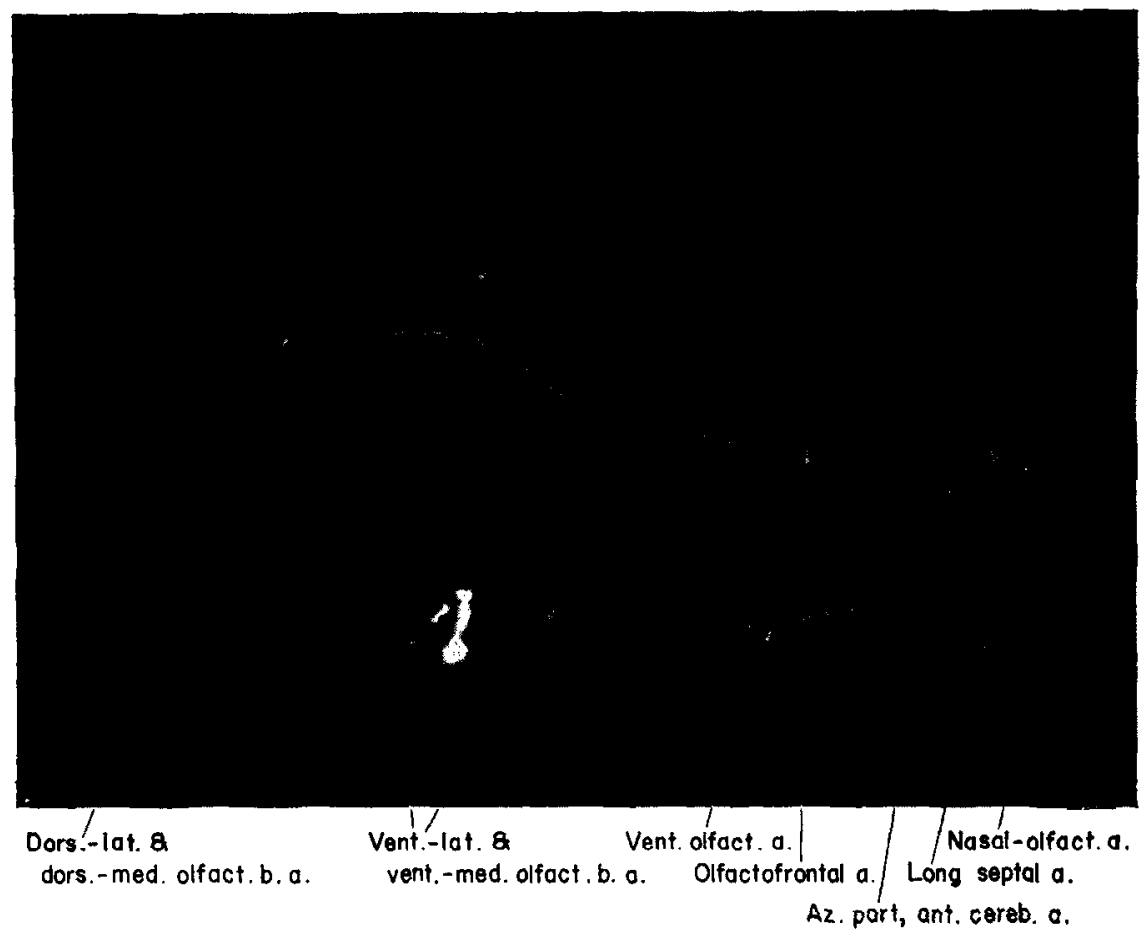

FIG. 1. View of arteries supplying the olfactory bulb and rostromedial forebrain structures. Specimen injected with RTV-11 silicone rubber and cleared in glycerin, as are all other pictured specimens for the paper except where noted. Scale, $1 \mathrm{~mm}$.

four major vessels that encompass the bulb (Fig. 1). Two clorsal vessels arise from a common trunk, the olfactofrontal artery. This stem vessel arises from the azygos anterior cerebral artery, usually at its most rostral limit, and courses in a rostral direction where medial and lateral olfactory branches supply the dorsum of the bulb. Its frontal branch (unlabeled) occupies the olfactofrontal sulcus and continues a course along the rluinal fissure to connect with a branch of the middle cerebral artery. Ramifications of the frontal branch supply the dorsal portions of the olfactory stalk, prepiriform cortex, ${ }^{3}$ and adjacent frontal cortex. Two ventral olfactory

3 The term septum is used in a general sense after the definition of Fox (23) and includes the basal structures lying beneath the corpus callosum in the anteromedial wall of the hemisphere, extending laterally as far as the lateral ventricle. The prepiriform cortex is meant to refer to the cortex located between the lateral olfactory tract and the rhinal fissure. The caudal extent of the cortex is near the line where the middle cerebral artery makes the lateral traverse. The periamygdaloid cortex refers to the cortex overlying the nuclear masses of the amygdala whereas the piriform cortex is located more posteriorly and includes those structures located between the hippocampus and rhinal fissure. 


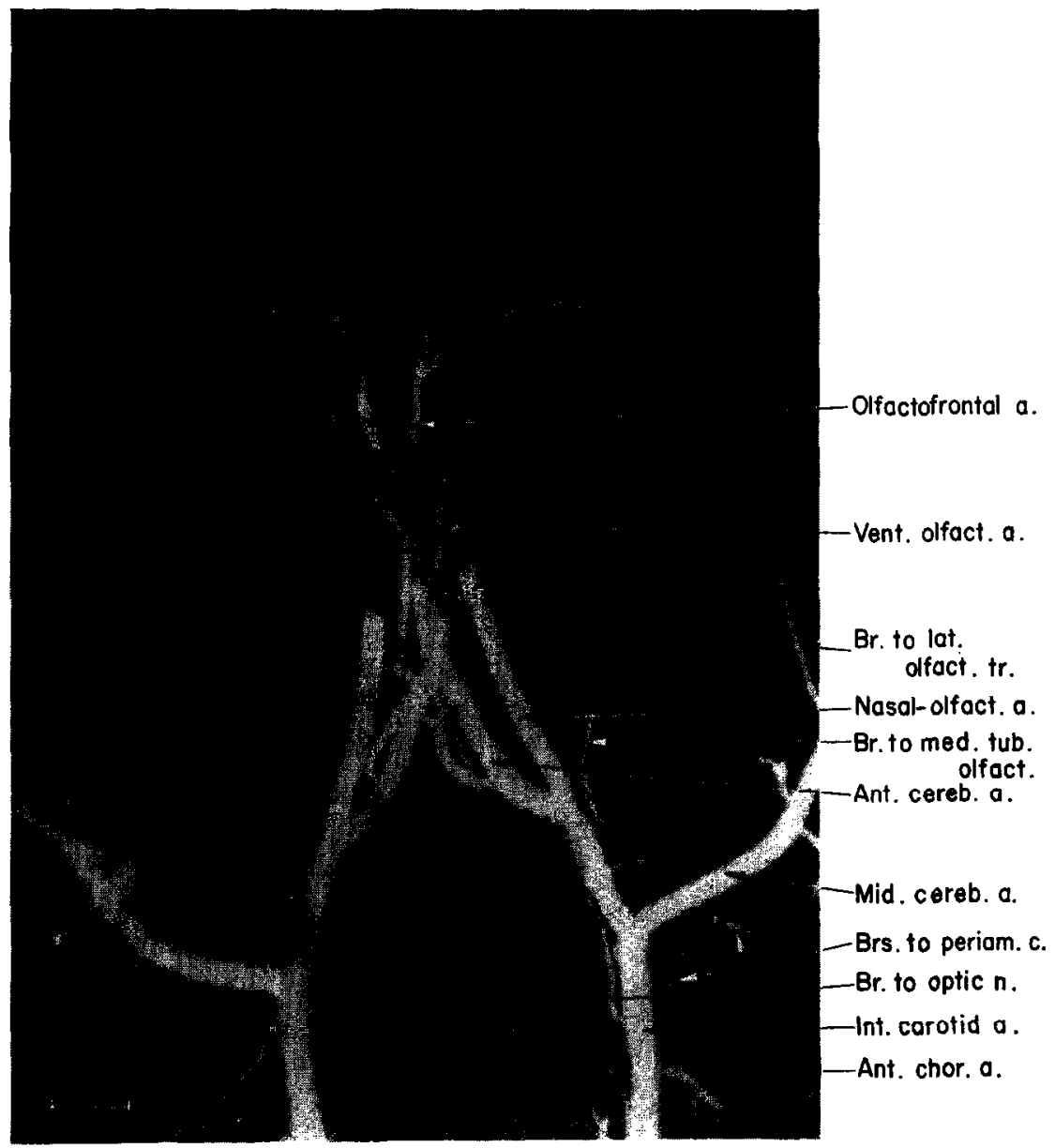

Fig. 2. Basal view of arteries stemming from the rostral portion of the circle of Willis to supply the olfactory bulb and associated structures. Scale, $1 \mathrm{~mm}$.

bulb arteries, one medial and the other lateral, stem from the common ventral olfactory artery (Fig. 1), a branch usually of the azygos anterior cerebral artery. Anastomotic connections between medial and lateral dorsal vessels form arcades providing branches to the bulb and accessory bulb and connections between dorsal and ventral vessels are evident (Fig. 1). Small ramifications penetrate the bulb at an angle perpendicular or normal to the surface to supply laminae with different vascular volumes. Branches of the nasal-olfactory artery anastomose with the medial olfactory vessels before entering the nasal cavity where its major fields are located. Such surface anastomotic patterns between vessels may provide collateral sources to butb structures in the event of a major branch occlusion. 
Ramifications of the ventral olfactory artery and the anterior cerebral artery travel in a rostrolateral direction (Fig. 2) to supply, in course, the rostral region of the horizontal limb of the tract and nucleus of the diagonal band of Broca, the small medial olfactory tract, the medial aspect of the tuberculum olfactorium, the anterior olfactory nucleus, the islands of Calleja, the nucleus accumbens, the rostral portions of the medial forebrain bundle, and the medial regions of the head of the caudate nucleus. Other vessels stem from the middle cerebral artery to supply more lateral portions of the field. A large vessel traverses in a parallel direction the lateral olfactory tract (Fig. 2) to supply it and the rostrolateral region of the head of the caudate nucleus.

Arterial supply of the septum. The septum (see footnote 3) receives its major blood supply from vessels stemming from the anterior cerebral artery (Figs. 1 and 3). A more detailed account of the vascular supply and drainage

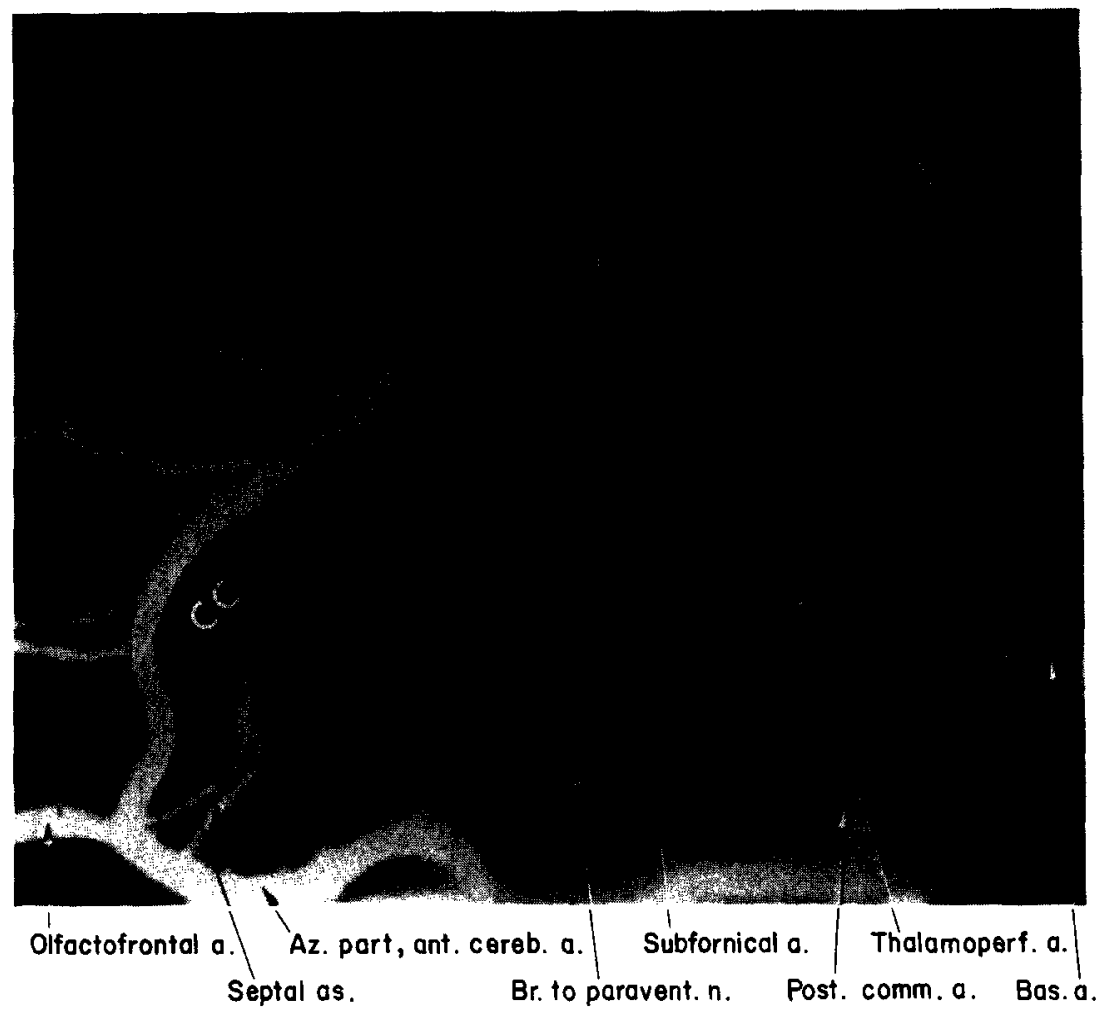

FIg. 3. Sagittal view of arteries supplying the septum, cingulate and retrosplenial cortex, and other structures. Note long intramedullary course of thalamoperforating arteries entering at the midbrain level. Transecting these vessels in a midbrain decerebration procedure would have grave influences on forebrain structures. Scale, $1 \mathrm{~mm}$. 


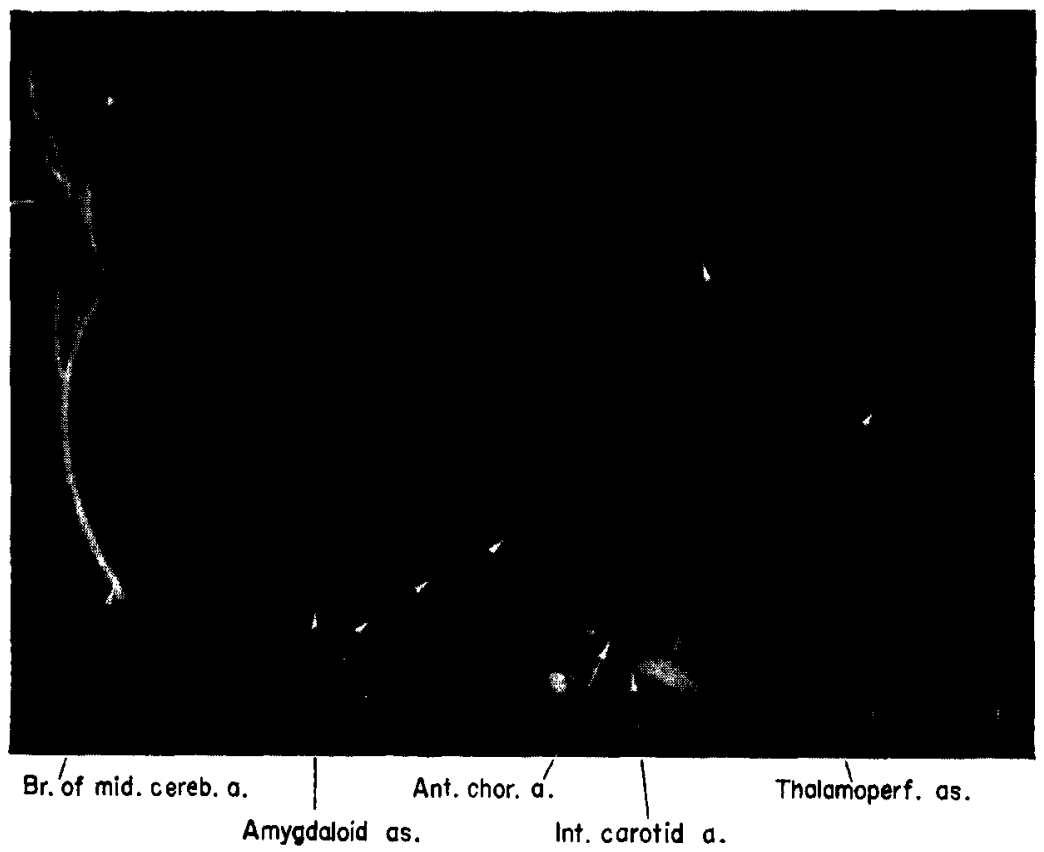

FIG. 4. Frontal view of arteries supplying the amygdala. Most lateral ramus indicated by drawn extension of the vessel branched from the middle cerebral artery. Thalamoperforating rami supply portions of the thalamus. Scale, $1 \mathrm{~mm}$.

of the rat septum was presented earlier by Coyle (12). Inclusion of a general account of the arterial supply here is to avoid omission of a major rhinencephalic region. Two sets of arteries arising from the azygos anterior cerebral artery, the long and short septal arteries, supply the septum.

The short septal arteries are more numerous than the long ones. Both sets course from a rostromedial to caudolateral position. Along the vertical coordinate, the vessels extend from an inferior to superior position.

Short septal arteries and the long ones, to a degree, supply rostral septal structures including medial, lateral, and dorsal septal nuclei, and the vertical limb of the tract and nucleus of the diagonal band of Broca. The anterior continuation of the hippocampus receives supply from the short septal arteries and unnamed branches of the anterior cerebral artery. The most caudal septal structures receive supply from the long septal arteries coursing superior to the anterior commissure and vessels were traced into the rostral end of the ventral hippocampal commissure, septal portion of the descending column of the fornix, and septal nuclei caudal to the anterior commissure. Intracerebral vascular connections between short or long vessels were not evident in the preparations; potential collateral supply through capillary meshworks could not. he investigated adequately in the 
silicone preparations. A rostral septal lesion or object implant may well interrupt vessels supplying more caudal septal structures. Caudal septal degeneration patterns as observed in animals where septal nuclei and fiber bundles disappear following a more rostral lesion may in fact relate to poor or no collateral interchange among the smaller vessels. Such degeneration patterns in the septum and hippocampus and their vascular basis is a current topic of our interest and are being pursted in detail in appropriate preparations.

Arterial supply of the cingulate cortex. The azygos anterior cerebral artery courses superior to the corpus callosum and then extends more or less parallel to it to supply it, the iduseum griseum, the longitudinal striae, and, in the posterior region, the fornix superior. Branches penetrate the cerebral substance at an angle approximately normal to the surface to nourish the cingulate cortex (Fig. 3) and extend onto the lateral surface of the hemisphere to supply frontal, parictal, and occipital cortices. Extensive vascular connections were made with numerous branches of the middle cerebral artery on the lateral hemisphere surface (12). Transections of the corpus callosum from above most likely sever the laterally directed branches and involve the anterior cerebral artery. A ventral approach could spare such involvements. The subfornical artery arises at about midcourse of the rostral caudal extent of the supracallosal cerebral vessel (Fig. 3). The vessel traverses a course around the splenium of the corpus callosum to pass rostralward to supply the subfornical organ (54). Other branches (Fig. 3, unlabeled) from the paired portion of the anterior cerebral artery anastomose with ramifications from the posterior cerebral artery in occipital, retrosplenial, and dorsal subicular fields. Vascular supply to the dorsal hippocampal commissure, subcallosal portion of the fornix superior, and caudal region of the ventral hippocampal commissure appears to receive from both the anterior and posterior cerebral circulation, with a few branches extending across the midline. The vascular supply to these fiber bundles is from small rami of the nearby arteries. Further analyses with a more refined technique seem appropriate, as these fibers are frequently transected without regard for consequences of possible large venous field involvements.

Arterial supply of the periamygdaloid cortex, anygdala, and piriform cortex. Several ramifications from the middle cerebral artery and internal carotid artery (Fig. 2) supply the periamygdaloid cortex (see footnote 3) and anygdala. The first branch of the anterior choroidal artery (Fig. 4) usually traverses a superficial course supplying ramifications to the cortex medial to the free edge of the tentorium cerebelli and to the periamygoid cortcx. Side ramifications course through the cortex in a dorsocaudal direction, divide into forkerl branches, and supply the central and medial regions 


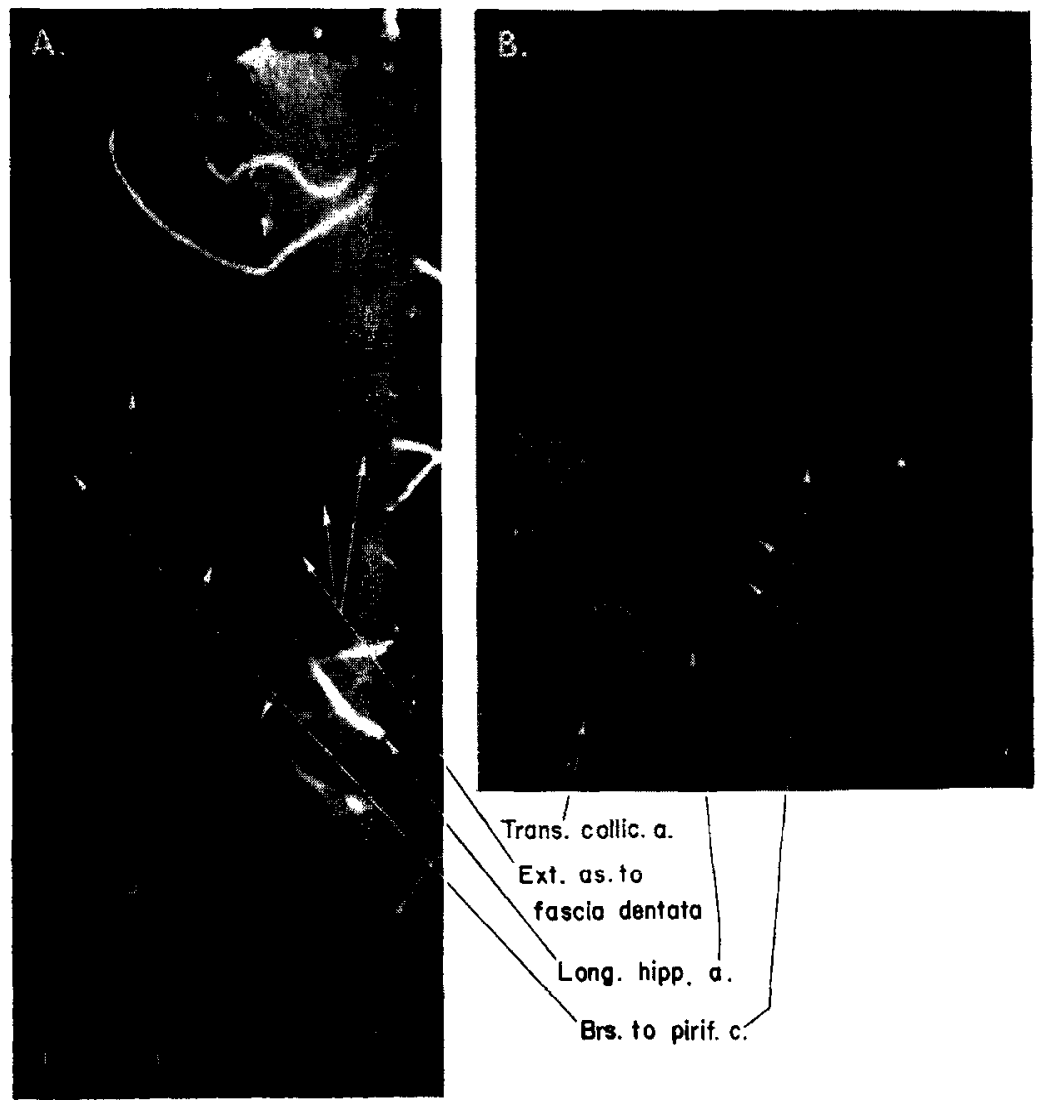

FIG. 5. A. Caudomedial view of left hippocampal formation. Note longitudinal hippocampal artery at the porta of the hippocampal fissure with transverse arteries to the piriform cortex and external blade of the fascia dentata. Transverse hippocampal arteries in fissure are not visible. Scale, $1 \mathrm{~mm}$. B. Caudal view of arteries on piriform cortex of right hemisphere. Uncleared specimen injected with silicone rubber thoroughly mixed with a small amount of India ink. Scale, $1 \mathrm{~mm}$.

of the amygdaloid mass. The stem vessel continues over the surface of the cortex to anastomose with branches from other cerebral vessels. A second branch arising from the anterior choroidal artery or the stem vessel supplying the amygdala courses in the transverse cerebral fissure and sends branches lateralward to supply the most medial region of the amygdala. The anterior amygdaloid area and most lateral amygdala region receive supply from rami of the middle cerebral artery.

The entorhinal, parasubicular, presubicular, subicular, and prosubicular structures receive supply from the longitudinal hippocampal artery, a branch 
of the posterior cerebral artery in rat. Several vessels stem from the longitudinal hippocampal artery (Fig. 5A, B) to supply the more lateral structures including the presubicular area 49 and entorhinal area 28 as illustrated by Krieg (40). One branch is often larger than the others (Fig. $5 \mathrm{~B})$. The vessel follows a course superiorly towards the rhinal fissure located in a more lateral position. In course, the vessel divides into smaller rami to nourish entorhinal structures. Distally, anastomoses of the vessels supplying the entorhinal cortex are made with branches of the middle cerebral artery. (Fig. 8).

Arterial supply of the hippocampal formation and nearby structures. In most brains examined, the posterior cerebral artery distal to joining the posterior communicating artery ramifies into three trunks (Figs. 6, 8). One trunk is the longitudinal hippocampal artery, a second is the continuation of the posterior cerebral artery, and the third vessel is the transverse collicular artery. Initially the three vessels are located in the transverse cerebral fissure. The transverse vessel traverses a course across the crus

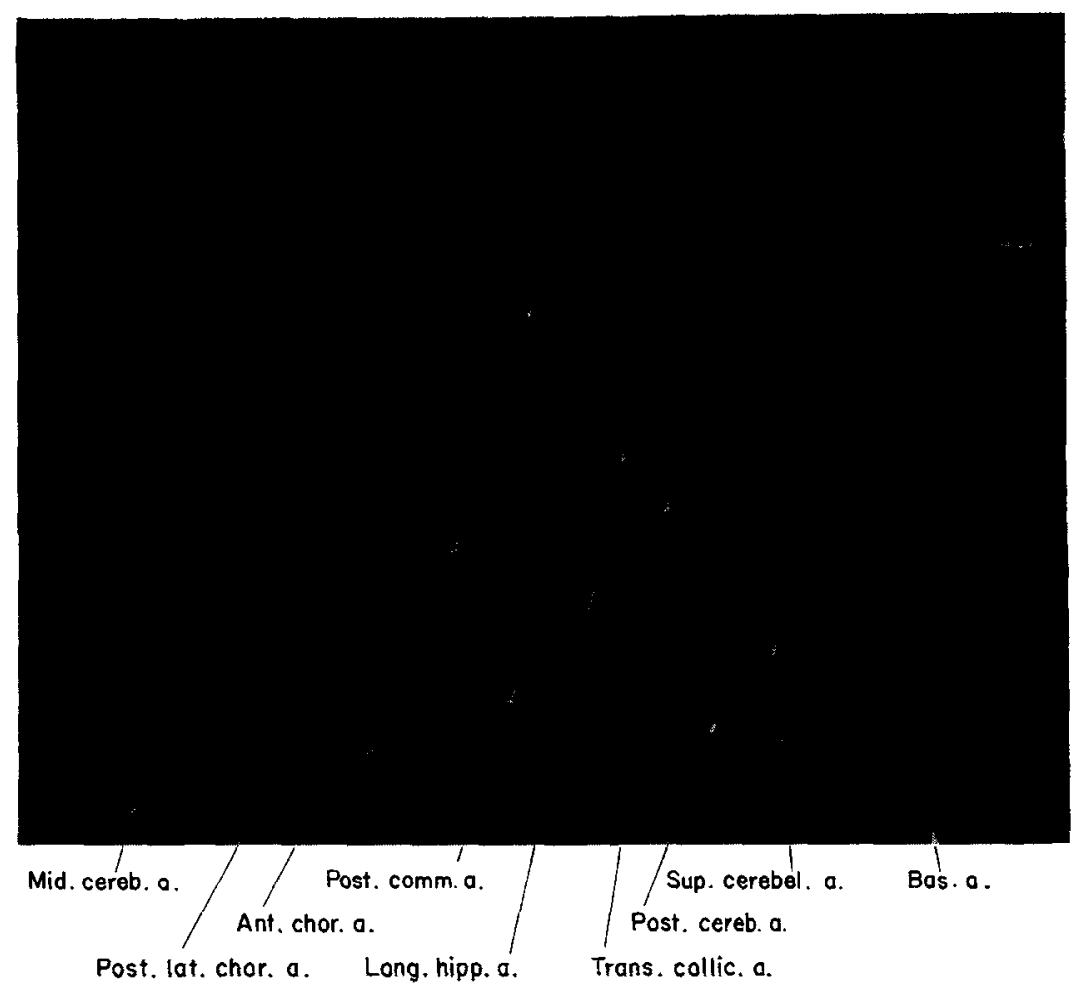

FIG. 6. Lateral view of basal forebrain and brain stem arteries. Rostral structures towards left, caudal ones to the right. Cerebral cortex, deep telencephalic white, and hippocampal formation dissected. Anterior choroidal artery disrupted. Scale, $1 \mathrm{~mm}$. 


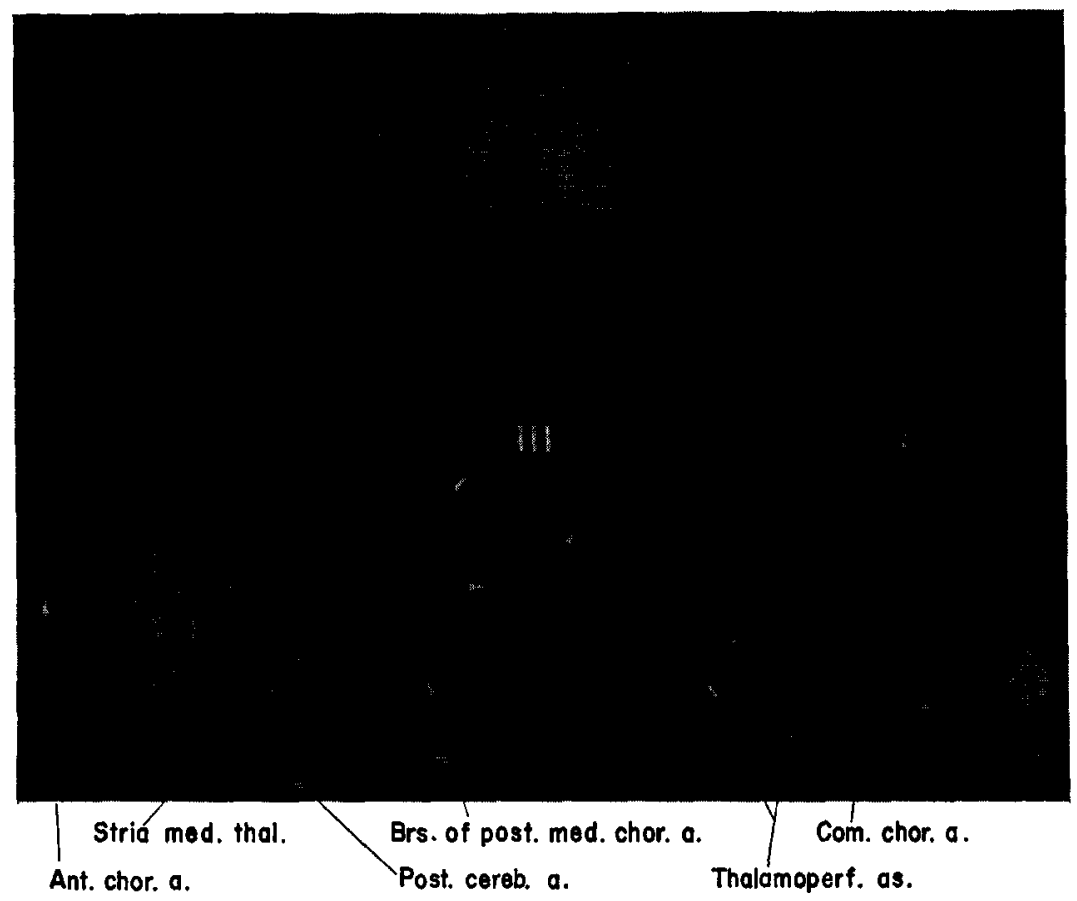

FIg. 7. View of arteries on the caudodorsal surface of the thalamus. Telencephalic structure dissected. Note posterior medial choroidal artery traverses from caudal (C) to rostral (R) regions of the stria medullaris thalami. Note formation of loop between posterior cerebral artery and anterior choroidal artery. Perfusion material as for specimen in figure 5B. Scale, $1 \mathrm{~mm}$.

cerebri, brachium of the inferior colliculus, and ascends in the transverse collicular sulcus to supply mesencephalic and caudal diencephalic structures in course. The posterior cerebral artery follows a more rostral path coursing over the caudal region of the thalamus. Terminal branches of the posterior cerebral artery perforate the thalamus to supply the superior fields (Fig. 7) and provide the posterior medial choroidal artery (Fig. 7) supplying the choroid plexus of the third ventricle. An arterial loop was generally established between the posterior lateral choroidal artery (usually a branch of the posterior cerebral artery, but occasionally of the longitudinal hippocampal vessel) and the anterior choroidal artery. The vessel distal to the junction, referred to as the common choroidal artery (Fig. 7), often joined a terminal branch of the posterior medial choroidal artery (Fig. 7) to form a second loop between the posterior circulation and the internal carotid artery. The anterior, posterior lateral, and common choroidal arteries supply the choroid plexus of the lateral ventricle. No rami could be traced to the hippocampus, 
The longitudinal hippocampal artery traverses a course parallel to the longitudinal axis of the hippocampus. The vessel is located in the porta ${ }^{4}$ of the hippocampal fissure (Fig. 5), supplies branches that nourish the fascia dentata and hippocampus as well as subicular and entorhinal structures. The vessel provides a massive set of transverse arteries (Figs. 8 and 9) that course in the hippocampal fissurc. The transverse vessels follow a course nearly normal to the longitudinal artery (Fig. 9). In the septal half of the hippocampus, but not at its most rostral extent, the transverse vessels are at an angle of approximately $45 \mathrm{deg}$ to the sagittal plane. In the temporal half the vessels are more closely spaced. Several transverse arteries frequently ramify from a common stem arising from the longitudinal vessel to supply branches to cornu ammonis with ramifications being most numerous in CA3 structures adjacent to the fimbria. The internal blade ${ }^{2}$ of the fascia dentata, CA1, adjacent prosubiculum, and subiculum appear to receive few branches from these transverse hippocampal arteries. The fascia dentata and subicular fields also receive from separate smaller diameter and less branching transverse vessels stemming from the common stem or longitudinal vessel. Vessels supplying the internal blade (see footnote 2) of the fascia dentata loop around its end to enter the area dentata. Field distributions in the hilum as distinct from those supplied by arteries nourishing the external blade (see footnote 2) (Fig. 5A) and entering the so-called fimbriodentate sulcus remain to be clarified. Separate supplies to CA4 and that portion of CA3 within the hilum are currently being investigated in appropriately prepared specimens. Contributions to the finbria, alveus, and hippocampus by the anterior choroidal artery or common choroidal artery coursing parallel to, but external to, the fimbria in the choroidal fissure were not observed in the silicone preparations.

\section{DISCUSSION}

In several respects the basic arterial patterns in rat forebrain structures were similar to observations made by Duret (19-21), Beevor (7), She11shear (53), Abbie (1-3), Scharrer (51) and Gillilan (25-27) for a series of vertebrates including man but not rat. A summary of earlier findings on the cerebral vasculature dating from the investigation published by Haller in 1781 can be found in a report by Duret (20).

Duret (19) and Beevor ( 7 ) considered the cerebral arteries in man to be cortical or basal vessels. The cortical components, being phylogenetically more recent, supply the cerebral cortex and deep telencephalic white while the older basal arteries nourish subcortical structures. Distinct differences

4 The term porta of the hippocampal fissure is used to designate the location in the extramedullary space, that is, at the junction of the transverse cerebral fissure and the partially obliterated hippocampal fissure (35). 


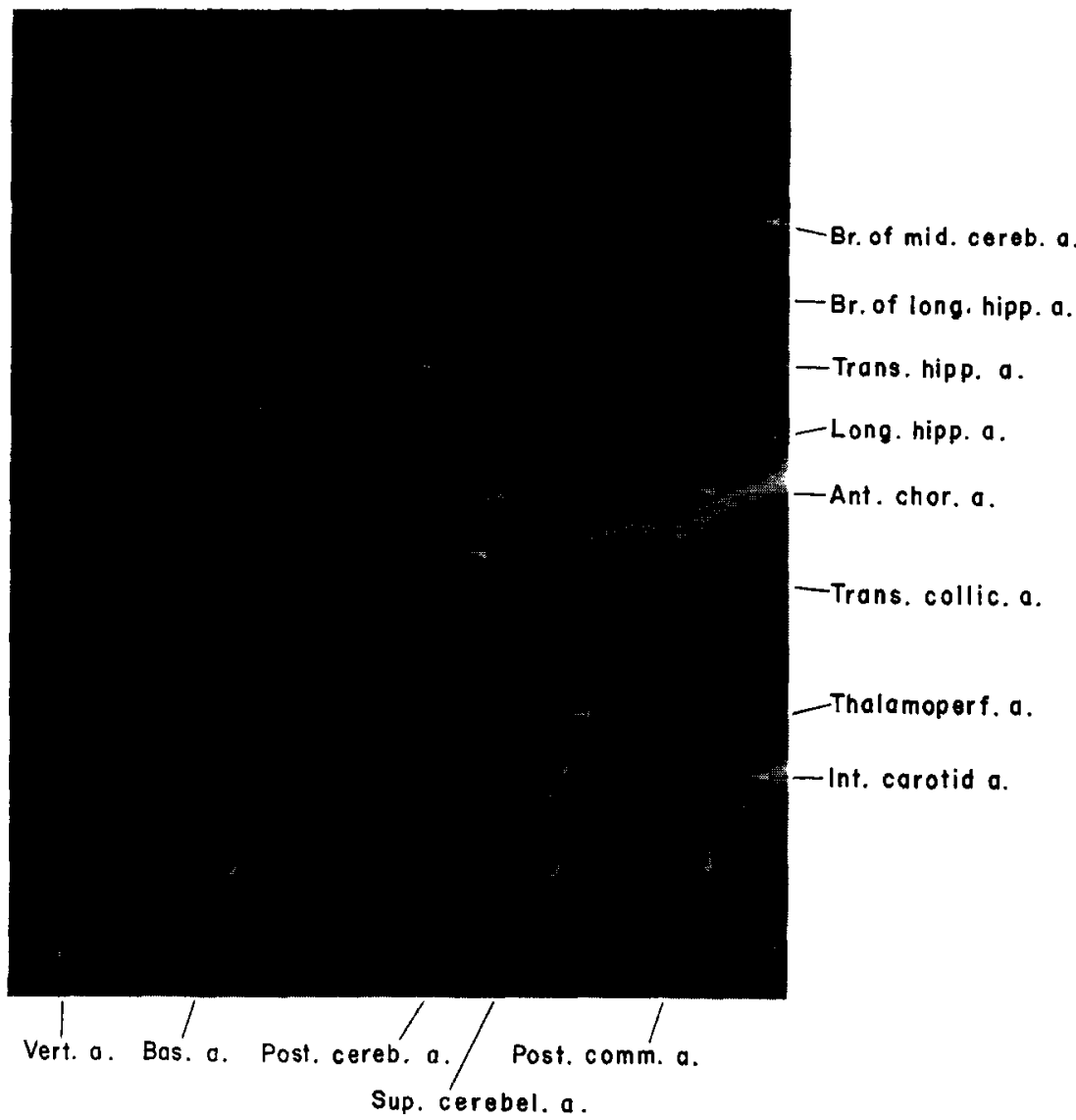

FIG. 8. Basal view of brain stem and caudal forebrain arteries. Note curved shape of transverse hippocampal vessels and anastomoses between branches of the middle cerebral artery and rami of the longitudinal hippocampal artery. Scale, $1 \mathrm{~mm}$.

such as type and number of anastomoses, collateral linkages, length, and branch patterns of intracerebral vessels exist between the two components.

Duret (20), Beevor (7), and others, including Gillilan (27), observed anastomoses between the three cerebral arteries at the confines of their areas in a variety of vertebrates including man. Ramifications of a cortical artery anastomose freely in the arteriolar plexus on the surface of the brain. Collateral supplies are evident on the surface of the olfactory bulb and exist on the surface of the cingulate and piriform cortex in rat. All three regions could receive blood from rami of the middle cerebral artery. Intracerebral anastomoses were not observed. While collateral supply via intracerebral arterial anastomoses may exist, convincing anatomical evidence for them and for arteriovenous shunts is meager. 
Vascular patterns observed in the septum, amygdala, and hippocampus were of a much different organization. The rostral septum is represented on the cerebral surface, yet anastomoses were not evident. The vessels follow a relatively long intracerebral course. Most septal arteries did not course perpendicular to the long axis of the septum, but rather were arranged ncarly parallcl to it; possibly the pattern was secondary to the mode of embryogenesis. The vessels branch most profusely near their endings. Similar ramification patterns were observed in the amygdala and appear to characterize the basal arteries there as in the hippocampus. Field distribution sizes of entering intracerebral basal arteries in the amygdala seemed to be larger in many instances than those of neocortical arteries as judged from branching patterns and vessel diameters. Quantitative measurements were not made.

Occlusion of the caudlally directed intracerebral vessels located in the medial septum would be expected to have profound influences on more



FIG. 9. Dorsal view of hippocampal vessels following maceration and telencephalic dissections. Septal pole to the left. Top edge of figure nearly parallels the sagittal plane. Note approximate $45 \mathrm{deg}$ angulation of the longitudinal hippocampal artery and transverse hippocampal vessels to the sagittal plane. Forked branches of the transverse hippocamjal arteries can be seen. Scale, $1 \mathrm{~mm}$. 
caudal septal structures. Involvements could extend to include the descending column of the fornix. Vascular disturbances in the medial septum or vertical limb of the diagonal band of Broca may modify septal cell pacemaking influences on neurons in the hippocampus and hippocampal formation outputs on fibers in the descending column of the fornix. Certainly, the shape and extent of septal lesions produced by passing current through an electrode implicate profound vascular involvements as evidenced from published pictures. One would wonder about the functional state of fibers in the descending column of the fornix and ventral hippocampal commissure. In utilizing histologic controls, examination and assessment of all structures supplied by vessels near or passing through a lesion site should be undertaken.

Arterial patterns in the amygdala would suggest that the phylogenetically older cortical, medial, and central nuclear masses could be selectively dcstroyed by occlusion of rami stemming from the anterior choroidal artery and the collateral source vessel. The basal lateral complex developing later in ontogeny as demonstrated by Humphrey $(37,38)$ and of more recent phylogenetic origin would be spared because of supply from branches of the middle cerebral artery.

Similarly, vessels in the hippocampal fissure could be subject to injury during or following lesion placement in the lascia dentata, hippocampus, or subiculum. The lesion could extend to include vessels in the partially obliterated hippocampal fissure or induce retrograde vasospasm along vessels located in the cerebral substance. The result would be partial or whole field loss depending upon the number and distribution of vessels involved. Of all places along the septal-hippocampal axis, transection of the fornix body would cause the least amount of damage to arteries of passage: Consideration should be given to possible involvements of the supracallosal vessels and sinuses.

Earlier physiologic studies by Andersen et al. (6) demonstrated that evoked responses along the perforant pathway, mossy fibers, Schaffer collaterals, and CA1 pyramidal cell axons in the alveus were of greatest magnitude along a tissue slice or lamellae when these structures were stimulated. The long axis of the slice was oriented transverse to the longitudinal hippocampal axis. The anatomical study of Lorente de Nó (43) and the experimental investigations by Blackstad et al. (9), HjorthSimonsen (34), and others demonstrated that topgraphic fiber distributions in the hippocampal formation provide an anatomical basis for the observed evoked responses. Andersen et al. (6) noted blood vessels in the hippocampal fissure followed nearly the same course as mapped evoked responses in rabbit, suggesting certain vascular elements parallel the arrangement of fibers and associated cells of a lamella. Adjacent transverse hippocampal 
arteries could relate to neuronal fields much as radicular arteries relate to the spinal cord: Both supply structures that may develop from segmented units. Studies are underway to measure the space between the transverse arteries and to ascertain field distribution sizes. At the temporal end of the hippocampus the vessels were more closely spaced as noted for rabbit by Nilges (47) and the same was found in this study for rat. At the septal end, the transverse vessels were longer and course nearly parallel to the sagittal plane as do the perforant path fibers (35). If the ressels represent hippocampal segmentation, consistency in width, length, shape, and number of segments per unit distance is probably least at the polar ends and greatest near midcourse along the longitudinal axis for rat. Certainly, the vascular pattern would suggest a segmental organization to the hippocampus, whereas vascular organization in subicular and entorhinal structures is quite different and should receive further study.

\section{REFERENCES}

1. AввiE, A. A. 1932-1933a. The blood supply of the lateral geniculate body, with a note on the morphology of the choroidal arteries. J. Anat. 67: 491-521.

2. Аввıе, А. A. 1933b. The clinical significance of the anterior choroidal artery. Brain 56: 233-246.

3. Aвbie, A. A. 1933-1934. The morphology of the forebrain arteries, with especial reference to the evolution of the basal ganglia. J. Anat. 68: 433-470.

4. Akmayev, I. G. 1971. Morphological aspects of the hypothalanic-hypophyseal system. III. Vascularity of the hypothalamus, with special reference to its quantitative aspects. Z. Zellforsch. Mikrosk. Anat. 116: 195-204.

5. Andy, O. J., and H. Stephan. 1964. "The Septum of the Cal." Thomid, Springfield, Illinois.

6. Andersen, P., T. V. P. Bliss, and K. K. Skrede. 1971. Lamellar organization of hippocampal excitatory pathways. Exp. Brain Ris. 13: 222-238.

7. Beevor, C. C. 1907. The cerebral arterial supply. Brain $30: 403-425$.

8. Blackstad, T. W. 1956. Commissural connections of the hippocampal region in the rat with special reference to their mode of termination. J. Comp. Nourol. $105: 417-538$.

9. Blackstad, T. W., K. Brink, J. Hem, and B. Jeune. 1970. Distribution of hippocampal mossy fibers in the rat. An experimental study with silver impregnation methods. J. Comp. Neurol. 138 : 433-449.

10. Brown, J. O. 1966. The morphology of circulus arteriosus cerebri in rats. Anat. Rec. 156: 99-106.

11. Coyle, P. 1975a. Transverse and longitudinal hippocampal veins in rat. Anat. Rec. 181 : 527-528.

12. Coyle, P. 1975b. Arterial and venous patterns in rat septal structures. In "International Symposium of the Septal nuclei." J. F. DeFrance [Ed.]. Wayne State Press, Detroit (in press).

13. Clarke, S. L. 1929. Innervation of the blood vessels of the medulla and spinal cord. J. Comp. Neurol. $48: 247-265$. 
14. Cratgie, E. H. 1930. The vascular supply of the archicortex of the rat. I. The albino rat (Mus norvegicus albinus). J. Comp. Neurol. 51: 1-11.

15. Cratgie, E. H. 1931a. The vascular supply of the archicortex of the rat. II. The albino rat at birth. J. Comp. Neurol. $52: 353-357$.

16. CRaigie, E. H. 1931b. The vascular supply of the archicortex of the rat. III. The wild norway rat (Mus norvegicus) in comparison with the albino. J. Comp. Neurol. 52 : 359-364.

17. Craigie, E. H. 1954. Vascular patterns of the developing nervous system, pp. 28-51. In "Biochemistry of the Developing Nervous System." H. Waelsch [Ed.]. Academic Press, New York.

18. Crosby, E. C., T. Humphrey, and E. W. Lauer. 1962. "Correlative Anatomy of the Nervous System," p. 412. Macmillan, New York.

19. Duret, H. 1874a. Recherches anatomiques sur la circulation de l'encéphale. Arch. Phys. Norm. Path. Serie 2, 1: 60-91.

20. Duret, H. 1874b. Recherches anatomiques sur la circulation de l'encéphale. Arch. Phys. Norm. Path. Serie 2, 1: 316-353.

21. Duret, H. 1874c. Recherches anatomiques sur la circulation de l'encéphale. Arch. Phys. Norm. Path. Scrie 2, 1: 919-957.

22. Duvernoy, H. 1972. The vascular architecture of the median eminence, pp. 79-108. In "Brain-Endocrine Interaction. Median Eminence: Structure and Function Int. Symp. Munich 1971." K. M. Knigge, D. E. Scott and A. Weindl [Eds.] Karger, Basel.

23. Fox, C. A. 1940. Certain basal telencephalic centers in the cat. J. Comp. Neurol. $72: 1-62$.

24. Friede, R. L. 1966. "Topographic Brain Chemistry," pp.1-15. Academic Press, New York.

25. Gillillan, L. A. 1967. Comparative study of the extrinsic and intrinsic arterial blood supply to brains of submammalian vertebrates. J. Comp. Neurol. 130: 175-196.

26. Gillilan, L. A. 1972. Blood supply to primitive mammalian brains. J. Comp. Neurol. $145:$ 209-221.

27. Gillilan, L. A. 1974. Potential collateral circulation to the human cerebral cortex. Ncurology 24 : 941-948.

28. Glydon, R. St. J. 1957. The development of the blood supply of the pituitary in the albino rat, with special reference to the portal vessels. J. Anat. $91: 237-244$.

29. Green, J. D., and G. W. Harris. 1947. The neurovascular link between the neurohypophysis and adenohypophysis. Endocrinology 5 : 136-146.

30. Greene, E. C. 1935. Anatomy of the rat. Trans. Amer. Phil. Soc. N.S., 27 : $1-370$.

31. Halasz, B., B. Kosaras, and I. Lenguari. 1972. Ontogensis of the neurovascular link between the hypothalamus and the anterior pituitary in rat, pp. 27-34. In "Brain-Endocrine Interaction. Medium Eminence: Structure and Function Int. Symp. Munich 1971." K. M. Knigge, D. E. Scott and A. Weindl [Eds.]. Karger, Basel.

32. Hartman, B. 1973. The innervation of cerebral blood vessels by central noradrenergic neurons, pp. 91-96. In "Frontiers in Catecholamine Research." E. Usdin and S. H. Snyder [Eds.]. Pergamon Press, New York.

33. Hartman, B., and S. Udenfriend. 1972. The application of immunological techniques to the study of enzymes regulating catecholamine synthesis and degradation. Pharmacol. Rev. 24 : 311-330. 
34. HJorth-Simonsen, A. 1971. Hippocampal efferents to the ipsilateral cntorhinal area: an experimental study in rat. J. Comp. Nourol. 142: 417-438.

35. Hjorth-Simonsen, A., and B. Jeune. 1972. Origin and termination of the hippocampal perforant path in the rat studied by silver impregnation. $J$. Comp. Neurol. 144: 215-232.

36. Huber, G. C. 1899. Observations on the imervation of intracranial vessels. $J$. Comp. Neurol. 9 : 1-34.

37. Humphrey, T. 1968. The development of the human amygdala during early embryonic life. J. Comp. Nourol. 132: 135-165.

38. Humphrey, T. 1972. The development of the human amygdaloid complex, pp. 21-80. In "The Neurobiology of the Amygdala." B. E. Elefteriou [Ed.]. Plenum, New York.

39. Konig, J. F. R., and R. A. Klippet, 1963. "The Rat Brain. A Stereotaxic Attas of the Forebrain and Lower Parts of the Brain Stem." Williams and Wilkins, Baltimore.

40. Krieg, W. J. S. 1946a. Connections of the cerebral cortex. I. The albino rat. A. Topography of the cortical areas. J. Comp. Neurol. 81: 221-275.

41. Krieg, W. J. S. 1946b. Connections of the cerebral cortex. I. The albino rat. B. Structure of the cortical areas. J. Comp. Neurol. $81: 277-323$.

42. LoRENTE DE Nó, R. 1933. Studies on the structure of the cerebral cortex. I. The area entorhinalis. J. Psychol. Ncurol. 45: 381-438.

43. Lorente de Nó, R. 1934. Studies on the structure of the cerebral cortex. II. Continuation of the study of the ammonic system. J. Psychol. Ncurol. 46: $113-177$.

44. Moffat, D. B. 1957. The development of the hind-brain arteries in the rat. $J$. Anat. $91: 25-39$.

45. Moffat, D. B. 1961a. The development of the anterior cerebral artery and its related vessels in the rat. Am. J. Anat. 108:17-29.

46. Moffat, D. B. 1961b. The development of the posterior cerebral artery. I. Anat. $95: 485-494$.

47. Nilges, R. G. 1944. The arteries of the mammalian cornu ammonis. J. Comp. Neurol. 80 : 177-190.

48. Penfield, W. 1932. Intracerebral vascular netves. Arch. Nezrol. Psychiat. (Chicago) $27: 30-44$.

49. Prolo, D. J., and D. L. Strlwell, Jr. 1962. Arterial supply of the diencephalon and some associated areas of the rabbit brain. J. Comp. Neurol. 119: 229-254.

50. Reiniš, S. 1961. Changes in the relative vascularity of various parts of the central nervous system after the elimination of neocortex. Acta Anat. 46: 73-80.

51. Scharrer, E. 1940. Arteries and veins in the mammalian brain. Anat. Rec. $78: 173-196$.

52. ScRemin, O. U. 1970. The vascular anatomy of the rat's hypothalamus in stereotaxic coordinates. J. Comp. Ncurol. 139:31-52.

53. Shellshear, J. L. 1920. The basal arteries of the forebrain and their functional significance. J. Anat. 55: 27-35.

54. Spoerri, V. O. 1963. Uber die Gefassversorgung des Subfornikalorgans der Ratte. Acto Anat. 54 : 333-348.

55. Tsang, Y. C. 1936. Vascular changes in the lateral geniculate body following extirpation of the visual cortex. Arch. Neurol. Psychiat. (Chicago) 36: $569-577$.

56. Tsavg, Y. C. 1940. Vascular changes in the thalamic nuclei undergoing retrograde degeneration. Arch. Neurol. Psychiat. (Chicago) 44: 1237-1245. 
57. WeINDL, A. 1973. Neuroendocrine aspects of circumventricular organs. In "Frontiers in Neuroendocrinology," pp. 3-32. W. F. Ganong and L. Martini [Eds.], Oxford University Press, New York.

58. WeInd, A., and R. J. Joynt. 1972. The median eminence as a circumventricular organ. In "Brain-Endocrine Interaction. Median Eminence: Structure and Function Int. Symp. Munich 1971," pp. 280-296. K. M. Knigge, D. E. Scott, and A. Weindl [Eds.], Karger, Basel.

59. ZEMAN, W., and J. R. M. InNes. 1963. "Craigie's Neuroanatomy of the Rat." pp. 30-49. Academic Press, New York. 